\title{
Heart Rate Responses to Social Interactions in Free-Moving Rhesus Macaques (Macaca mulatta): A Pilot Study
}

\author{
Filippo Aureli, Stephanie D. Preston, and Frans B. M. de Waal \\ Emory University
}

\begin{abstract}
Heart rate telemetry was explored as a means to access animal emotion during social interactions under naturalistic conditions. Heart rates of 2 middle-ranking adult females living in a large group of rhesus macaques (Macaca mulatta) were recorded along with their behavior. Heart rate changes during 2 types of interactions were investigated, while controlling for the effects of posture and activity. The risk of aggression associated with the approach of a dominant individual was expected to provoke anxiety in the approachee. This prediction was supported by the heart rate increase after such an approach. No increase was found when the approacher was a kin or a subordinate individual. The tension-reduction function of allogrooming was also supported. Heart rate decelerated faster during the receipt of grooming than in matched control periods.
\end{abstract}

Group-living primates engage in a great variety of interactions with each other, the meaning and significance of which is not always clear to the human observer. Is being in proximity with a dominant individual of different consequence than being in proximity with a subordinate? Can allogrooming be a "service" in the sense that it creates physiological and psychological well-being in the recipient? Answers to such questions may greatly advance our understanding of how primate societies operate on the emotional level (i.e., how various social interactions are experienced by the participants and how such experiences in turn influence subsequent behavior).

Animal emotion has been mostly ignored as a research topic because of its presumed subjectivity (Panksepp, 1989). Recent perspectives in the animal and human literatures have reflected a desire to study emotion as a mediator between the perception of the social and physical environment and behavioral responses (for animal examples, see Aureli, 1997; Crook, 1989; Lott, 1991; for human examples, see Frijda, 1994; Panksepp, 1989; Rolls, 1995). Significant

Filippo Aureli, Stephanie D. Preston, and Frans B. M. de Waal, Living Links Center, Yerkes Regional Primate Research Center, and Department of Psychology, Emory University.

This research was supported by Grants R01-RR09797 and RR-00165 from the National Institutes of Health.

We thank Thomas Insel for encouragement and support; Richard Wagner, Chang-Kwei Lin, David Osgood, Katherine Paul, Brent Swenson, and the Yerkes animal care staff for expert assistance; Renee Allen and Melissa Emery for contribution to data collection, coding, and analysis; Gary Berntson for the computer program for artifact correction; Evan Byrne, Steve Porges, Kathlyn Rasmussen, Todd Riniolo, Orville Smith, and Darlene Smucny for advice during various phases of the project; and Susan Clarke, Thomas Insel, Gabriele Schino, Alfonso Troisi, and Richard Wagner for comments on previous versions of the article.

Correspondence concerning this article should be addressed to Filippo Aureli, Living Links Center, Yerkes Regional Primate Research Center, Emory University, Atlanta, Georgia 30322. Electronic mail may be sent to aureli@rmy.emory.edu. advances in neurophysiology allow researchers to go one step further and make inferences about emotion on the basis of behavioral and physiological changes, thus freeing emotion research from the inherent problems of introspective report (Davidson \& Sutton, 1995; LeDoux, 1995; Levenson, 1992; Panksepp, 1989).

Heart rate is a common physiological measure of human emotion, although its changes may be due to various psychological and neurophysiological processes (e.g., Cacioppo, Klein, Berntson, \& Hatfield, 1993; Ekman, Levenson, \& Friesen, 1983; Levenson, 1992). In nonhuman primates, changes in heart rate have been used to monitor responsiveness under various experimental conditions (e.g., Berntson, Boysen, Bauer, \& Torello, 1989; Boysen \& Berntson, 1989; Clarke, Mason, \& Mendoza, 1994; Manuck, Kaplan, Adams, \& Clarkson, 1989; Miller, 1967; Rasmussen \& Suomi, 1989) and to characterize individual variability in terms of dominance rank and personality (e.g., Kaplan, Manuck, \& Gatsonis, 1990; Smith, Astley, Chesney, Taylor, \& Spelman, 1986; Suomi, 1991).

Recent developments have made biotelemetry a useful method for measuring heart rate in naturalistic situations (Stohr, 1988). One can monitor heart rate in large enclosures with minimal disturbance to the subject while maintaining the complexity of interaction with group members. Although some studies have collected heart rate data from freemoving primates in their social groups, few have correlated heart rate with ongoing social behavior (Boccia, Reite, \& Laudenslager, 1989; Manuck, Kaplan, \& Clarkson, 1986; Smith et al., 1986). This deficit may stem from the difficulty to control for the pronounced effects of general physical activity on heart rate. Changes in activity level and posture are accompanied by strong changes in heart rate (Smith et al., 1993), and these effects could overshadow the possible emotional effects of social interactions.

The present pilot study explored heart rate telemetry as a means to access animal emotion during social interactions under naturalistic conditions, while controlling for the effects of posture and activity of the subject. We investigated 
heart rate changes associated with interactions that may provoke emotional states in two middle-ranking females belonging to a large group of rhesus macaques (Macaca mulatta). This species was chosen because it is characterized by an especially strict dominance hierarchy (de Waal \& Luttrell, 1989), making social interactions likely to cause social tension and anxiety and thus requiring effective mechanisms for tension reduction.

We focused on two types of interactions that we expected to elicit contrasting physiological responses. The first interaction consisted of the mere approach of a dominant individual. Behavioral and pharmacological evidence suggests that the approach by a dominant monkey causes anxiety-like emotion in the approachee, probably because of the risk of aggression. Self-directed behavior, such as self-scratching and self-grooming, is often associated with stressful situations in nonhuman primates (Maestripieri, Schino, Aureli, \& Troisi, 1992) and is decreased by anxiolytic drugs and increased by anxiogenic drugs (Schino, Perretta, Taglioni, Monaco, \& Troisi, 1996). In macaques, proximity to higher ranking group members increases the frequency of self-grooming (Troisi \& Schino, 1987) and self-scratching (Pavani, Maestripieri, Schino, Turillazzi, \& Scucchi, 1991), and anxiogenic drugs increase fear responses to the approach of the most dominant individual (Schino et al., 1996).

Increases in heart rate (Fredrikson, 1989; Ohman, 1993) and self-directed behavior (Waxer, 1977) are commonly associated with anxiety in human participants. Further, anxiogenic treatment of monkeys increases heart rate (Ninan et al., 1982). Therefore, we predicted an increase in heart rate following the approach by a dominant individual. As control measures, we used the heart rate changes following approaches by kin and by subordinate, unrelated individuals, which are less likely to result in aggression.

The second type of targeted interaction was allogrooming. Although the impression of relaxation in monkeys receiving allogrooming has inspired the tension-reduction hypothesis (Terry, 1970), little empirical evidence has been reported thus far. Preliminary reports suggested physiological support for this hypothesis (Smith et al., 1986). One study found a statistically significant decrease in heart rate while the subject, an adult female pigtail macaque (Macaca nemestrina), received grooming by others (Boccia et al., 1989). This study, however, did not take into account the posture and activity level of the subject. Comparisons of heart rate during the receipt of grooming with heart rate during self-grooming or allogrooming performance are confounded by the inherently lower level of activity during the receipt of grooming. In addition, a decline in heart rate during a grooming bout may simply reflect a transition in activity (e.g., from locomotion to resting) or posture (e.g., from sitting to lying down) before the onset of the bout. These problems were not addressed by Boccia et al.'s study.

Our study controlled for these potential confounds by using a paradigm in which observations of targeted grooming interactions were compared with matched control observations (de Waal, 1992). We compared heart rate changes in the groomee during the grooming bout with heart rate changes during control periods that were selected to match the initial heart rate value, the type and latency of previous activity transitions, the subject's posture, and the time elapsed from the beginning of the grooming. We predicted that heart rate would still be lower if the subject received allogrooming than during matched control periods.

\section{Method}

\section{Subjects and Housing}

The subjects of this study were 2 middle-ranking adult females ( 15 and 8 years old and weighing 10.4 and $8.2 \mathrm{~kg}$, respectively) that belonged to a group of 79 rhesus macaques (Macaca mulatta). The group was established in 1982, and at the beginning of the study in 1995, the group consisted of 2 adult males, 31 adult females, and 46 immatures. The group was housed in a $900-\mathrm{m}^{2}$ outdoor compound connected with indoor quarters at the Field Station of the Yerkes Regional Primate Research Center. Food was provided twice daily. Water was available ad libitum.

\section{Procedure and Data Collection}

Heart rate data were collected using the DataCol system (Mini-Mitter Co., Sunriver, OR). The subjects were subcutaneously implanted with a small transmitter ( $44 \mathrm{~g})$ in the back after anesthetization following various protocols (Ketamine, Propofol, and Telazol). The electrode locations were determined by monitoring the strength of the signal with an oscillographic ECG monitor. The electrodes were then sutured to the tissue with stainless-steel surgical thread to minimize motion artifacts. After a 10-day recovery period, the subjects were returned to the group and calibration software was used to fine tune the reception of the signal. Subjects did not show signs of discomfort due to the implant, and other group members ignored the implant after the first few hours. After about 6 months, the transmitter was surgically removed, again without any complication in the subject's health.

A dipole antenna was installed at about $6 \mathrm{~m}$ off the ground on an observation tower located on one side of the compound. Signal transmission was possible from any location in the compound, at distances up to $50 \mathrm{~m}$, but signal quality deteriorated over the 6-month life of the transmitter battery. Over time, problems also arose with signal transmission depending on the subject's posture, suggesting that either the leads attached to the electrodes had cracked and lost some insulation or some tissue grew on the electrodes, altering proper transmission. For 1 of the subjects, a new surgery was carried out to replace the transmitter, the leads, and the electrodes.

The antenna was connected to a receiver that transmitted heart beat data to a computer. The computer converted the data into instantaneous interbeat intervals and heart rates, which were automatically stored in a file along with the corresponding times.

Each data collection session consisted of up to $2 \mathrm{hr}$ of continuous recording of heart activity of 1 subject. At the same time, the behavior of the subject and a spoken commentary were videotaped while time markers were inserted in the heart rate data file to facilitate integration of behavioral codes into the file. Behavioral data included the occurrence of any social interaction involving the subject and the surrounding animals, along with changes of the subject's general activity and posture, including minimal movements of the head and limbs when the animal was stationary.

We also collected ad libitum data on unidirectional aggressive interactions, avoidance, and submissive signals (i.e., bared-teeth 
display; de Waal \& Luttrell, 1985) to assess dominance relationships between group members.

\section{Data Analysis}

Heart activity data were inspected for quality; potential artifacts in the interbeat intervals were identified and corrected by automated computer algorithms (Berntson, Quigley, Jang, \& Boysen, 1990). If too many beats were missing or altered by interference, we excluded the corresponding period of behavioral data from further evaluation.

From the $50 \mathrm{hr}$ of collected data, cases of approach and allogrooming that minimized confounding effects on heart rate were selected. Subjects needed to be in a stationary position (sitting or lying down) at the beginning of the event, and no shift from such a position could occur (cf. Manuck et al., 1986). We discarded cases during which other behavioral events (e.g., other approaches or aggression between nearby individuals) occurred. In addition, we discarded cases of approach by dominant individuals in which the subject showed overt signs of fear or submission (e.g., bared-teeth display).

A preliminary analysis of the data indicated that small movements of the subject's head and limbs were associated with small accelerations of the heart rate. These movements might not have a direct impact on heart rate but could be manifestations of the emotional responses to social interactions. Nevertheless, to distinguish emotional responses from the possible effect of pure physical activity, we excluded from the analyses those portions of data during which even small body movements occurred that could have confounded the predicted increase in heart rate (e.g., after the approach of a dominant individual).

An approach was defined as the arrival of one individual within $1 \mathrm{~m}$ of the subject while the subject faced the approacher with eyes open. Three types of approachers were considered: (a) individuals that were both dominant over and unrelated to the subject; (b) those that were closely related (i.e., mother-offspring or maternal sibling) to the subject; and (c) those that were both subordinate and unrelated to the subject. To emphasize the rank difference, we limited the selection of dominant approachers to the four topranking adult individuals in the group. Both subjects had only one close kin: an adult daughter for the older subject and the mother for the younger subject.

For each selected approach, a direct comparison of heart rate before and after the event was made. Periods of $5 \mathrm{~s}$ before and $5 \mathrm{~s}$ after the approach, in which the subject did not move the head or limbs, were selected. Mean heart rates during these periods were then compared to assess the effect of the approach. In some cases, the duration of these periods needed to be shortened to avoid the inclusion of movements. We discarded cases in which accelerating or decelerating heart rates before the approach, which were due to postural or activity changes or other events, would have biased our analysis.

Allogrooming was defined as picking through or slow brushing aside of the fur of a partner with one or both hands. The teeth and tongue could also be used in combination with the hands. We examined cases in which subjects were groomed by other group members while maintaining their eyes open (i.e., they were not asleep). As groomees, subjects were sitting or lying down and remained mostly immobile during the grooming bout. To obtain a measure of maximum heart rate change during grooming, we selected periods of $10 \mathrm{~s}$ during grooming bouts when heart rate reached the lowest values. Mean heart rates during these periods were then subtracted from mean heart rates during 10-s periods at the onset of grooming. In some cases, the duration of these periods was shorter than $10 \mathrm{~s}$ to exclude portions of data during which the subjects moved their head or limbs or readjusted their position.

Activity before the beginning of the grooming bout could also affect heart rate in a stationary individual. We compared heart rate changes in the subject while she was receiving grooming with matched control periods selected from the remaining data to match the initial heart rate value, the type and latency of previous activity transitions, the subject's posture, and the time elapsed from the beginning of grooming (range: 10-88 s).

The preceding requirements dramatically reduced sample size for analyses. Many instances of approach and allogrooming had to be discarded for at least one of the following reasons: (a) low quality of heart activity recording, (b) subject movement, (c) approacher identity did not meet our criteria, (d) appropriate matched control period was not found, or (e) other events occurred near the subject. For example, only $4 \%$ of the 561 approaches received by the older subject met the requirements for analysis. Similarly, only $8 \%$ of the 166 allogrooming bouts received by the 2 subjects could be used for analysis. Sample size was sufficient, however, to carry out nonparametric statistical analysis. Because we had clear predictions, we used one-tailed Wilcoxon matchedpairs tests with the significance level set at .05 . For each approach, we compared mean heart rate before and after the event. This analysis was done for approaches by dominant, subordinate, and closely related individuals. To test the tension-reduction function of allogrooming, heart rate changes during each grooming bout were compared with those during matched control periods for each of the 2 subjects.

\section{Results}

When heart rates before and after approach towards the subject were compared, the dominance status of the approaching individual proved to affect the response (see Figure 1). When the approacher was a dominant individual, the heart rate of both subjects increased after the approach (older subject: $n=8, T=0, p<.01$; younger subject: $n=9$, $T=1, p<.001$ ). In contrast, no difference was found when the older subject was approached by her adult daughter $(n=8, T=14.5, n s)$ or by a subordinate nonrelative $(n=8$, $T=17, n s)$. Also when these two data sets were combined, no significant difference resulted $(n=16, T=61, n s)$. For the younger subject, only two approaches by her mother could be used and, in both cases, a slight decrease in heart rate followed the approach. The approaches by subordinate, unrelated individuals toward the younger subject resulted in an increase in heart rate in 4 cases and a decrease in 3 cases. When the data sets for approaches by the mother and by subordinate, unrelated individuals were combined, no significant effect of the approach on the heart rate of the younger subject was found $(n=9, T=22, n s)$.

Figure 2 illustrates that the heart rate of each subject decreased over time during grooming bouts as well as during the corresponding matched control periods. The heart rate deceleration was, however, more pronounced while receiving grooming than during matched control periods. In the younger subject, the decrease in heart rate was more pronounced during each of the six grooming bouts analyzed than during the corresponding control periods. In the older subject, the same was true for five of the seven grooming bouts; in 1 case the decrease was slightly faster in the control period, and in another case no difference between grooming 


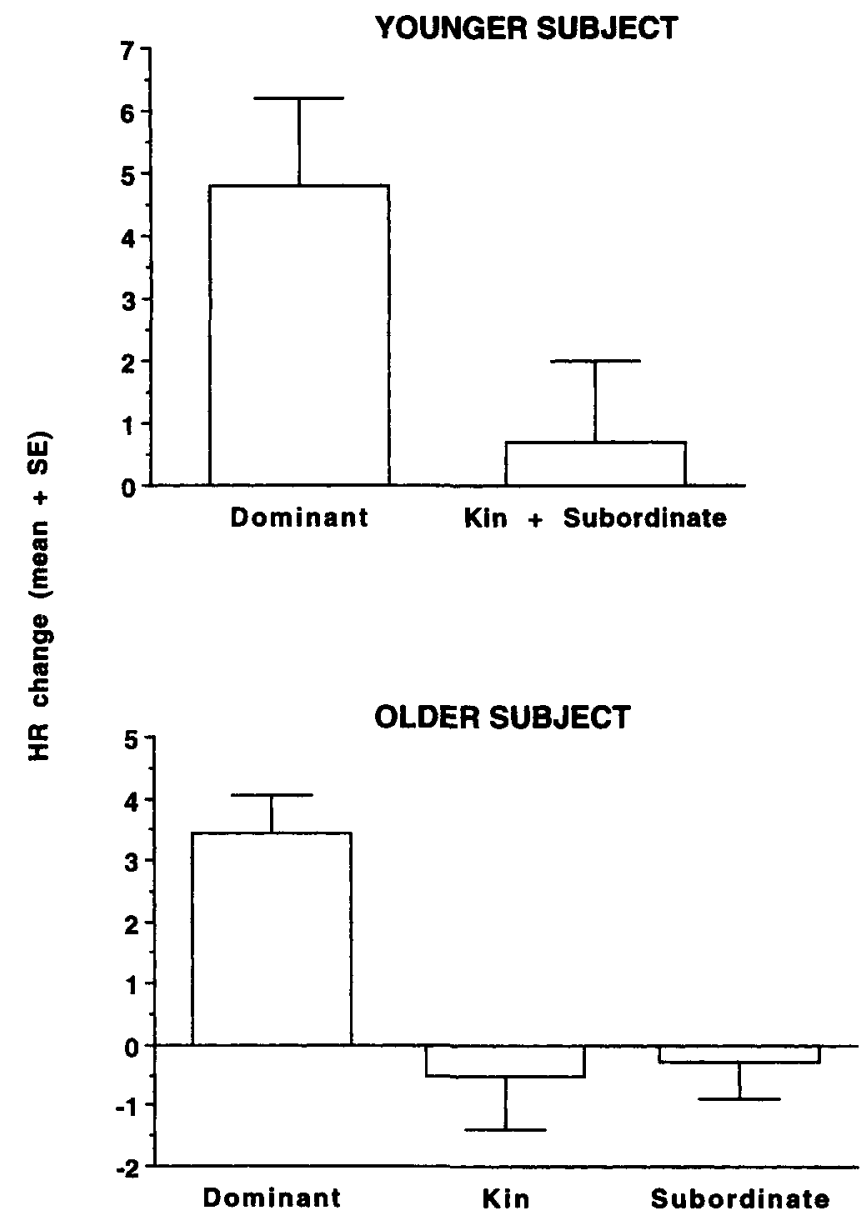

TYPE OF APPROACHER

Figure 1. Mean changes (after-before the approach) in heart rate (HR; beats per minute) of both the younger and older subjects during approaches by dominant, unrelated individuals; by kin; and by subordinate, unrelated individuals.

and control periods was found. When the data of the two subjects were analyzed together, a decelerating effect of receiving allogrooming on heart rate was found (mean values for allogrooming: -18.8 beats/minute; control: -10.5 ; $n=12, T=1, p<.001$ ).

\section{Discussion}

The present pilot study confirms that biotelemetry can be a useful tool for studying heart rate responses to social interactions in free-moving animals while controlling for posture and activity. Although our sample size was small, the predicted emotional responses to two types of social interactions were supported by the observed changes in heart rate.

Heart rate changes in response to socioemotional conditions are generally small (cf. Berntson et al., 1989; Ekman et al., 1983) compared with those for activity transitions (Smith et al., 1993). Therefore, under naturalistic conditions the subtle changes due solely to emotional states are hard to detect because they are often overshadowed by activity changes, including even small head or limb movements. In addition to confounds that are due to activity changes, there may be confounds related to the social setting. Under naturalistic conditions, the monkeys are fully involved in the social life of the group: They exchange various types of interactions in rapid succession and observe and react to ongoing interactions among other group members. All these social events may affect heart rate and thus complicate the isolation of emotional responses that are due to a single social interaction.

We tried to control for these potential confounds in our

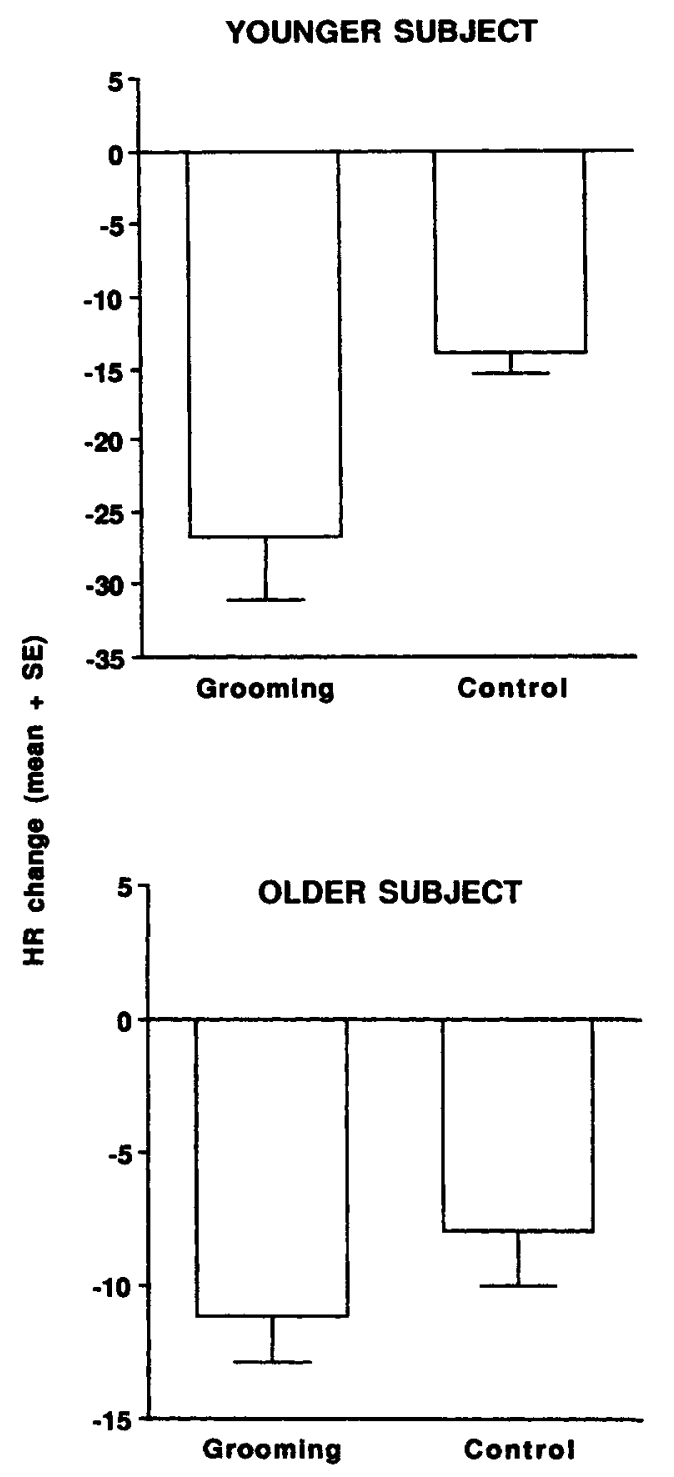

Figure 2. Mean maximum changes in heart rate (HR; beats per minute) of both the younger and older subjects during the receipt of grooming and matched control periods. See the Data Analysis section for the selection of the periods for maximum heart rate change calculations. 
study, even though this resulted in a sharply reduced number of observations suitable for analysis. The sample size used in our analysis is a poor reflection of the total amount of time put into data acquisition, tape coding, data editing, and selection of experimental and control periods, as evidenced by the number of hours of tape collected compared with the number of minutes actually used. Heart rate telemetry was therefore a labor-intensive, time-consuming procedure, but it still proved useful for our goal to study animal emotion during ongoing social interaction under naturalistic conditions.

\section{Approach and Anxiety}

The approach by a dominant individual was sufficient to provoke heart rate acceleration in 2 middle-ranking adult females living in a well-established social group of rhesus macaques. In contrast, the approach of the subject's kin or a subordinate nonrelative did not cause consistent heart rate responses. These results are in agreement with the view that the strict dominance hierarchy of this species creates social tension when animals interact with dominant individuals. If the mere proximity to higher ranking individuals entails some risk of being attacked, the increase in heart rate is likely to reflect anxiety as predicted by behavioral and pharmacological evidence (see the introduction). Under such circumstances, anxiety is an adaptive response to uncertainty and anticipated threat (Lazarus, 1991) because increased alertness and arousal allow the individual to take vigorous action if needed (Gray, 1987).

We need to be cautious, however, when interpreting these results. The increase in heart rate suggests that the approach by a dominant individual provokes a defensive response (Berntson et al., 1989; Graham, 1979), but it does not reveal the underlying neurophysiological processes. Heart rate can be elevated by sympathetic activation or by parasympathetic withdrawal. In addition, it is not clear whether anxiety-like emotion in primates always has the same autonomic expression. Emotional responses to potential danger are not necessarily associated with heart rate acceleration; in fact, the well-known mammalian orienting response is characterized by a decrease in heart rate (Berntson et al., 1989; Graham, 1979; Porges, 1995).

We selected approaches to eliminate the effect of movement on heart rate. This selection could have resulted in a failure to find the expected heart rate change because approaches by a dominant individual usually result in movement by the subordinate (e.g., submissive display, body shifting, crouching, retreat), which may reflect the level of anxiety. If the limited movement that accompanied the selected approaches was the result of the absence of anxiety-like emotion in the approachee, these approaches should not have produced the predicted heart rate increase (see the introduction). The fact that we did find heart rate acceleration following the approach of a dominant individual shows, however, that anxiety-like emotion is probably experienced by the approachee even in the absence of movement. Thus, our procedure was successful in distinguishing between emotional responses to approaches by different individuals while eliminating the possibility that the changes in heart rate were due to movements or activity changes. In addition, our findings suggest that biotelemetry may be a useful tool to study animal emotion in the absence of external signs of emotional states.

\section{Allogrooming and Tension Reduction}

Our findings on the effects of allogrooming support its hypothesized tension-reduction function (Terry, 1970), which has also been supported by data on self-directed behavior in macaques (Schino, Scucchi, Maestripieri, \& Turillazzi, 1988). Our study confirmed the heart rate findings of Boccia et al. (1989; see also Smith et al., 1986) but went a step further by controlling for activity and posture of the subjects (see the introduction and the Method section). That controls are crucial is evident from the heart rate decreases that can be attributed to reduced activity that is associated with grooming receipt (see matched control periods in Figure 2). Through comparisons with matched control periods, we were able to show that the effects of allogrooming were not confounded by activity transitions. In both of our subjects, heart rate deceleration was more dramatic while receiving grooming than in matched control periods. Interestingly, heart rate effects that are similar to those of allogrooming have also been found for petting or gentle touching by human experimenters in horses, rhesus macaques, and humans (Drescher, Gantt, \& Whitehead, 1980; Drescher, Hayhurst, Whitehead, \& Joseph, 1982; Feh \& De Mazieres, 1993).

The study of physiological, and possibly emotional, changes associated with allogrooming may provide insight into social organization. The empirical evidence for the tension-reduction function of allogrooming supports the view that allogrooming serves to establish, maintain, and improve social relationships (reviewed by Goosen, 1987). The relaxation provided by allogrooming is potentially highly beneficial, especially in species that experience high social tension. If allogrooming is a tension-reduction mechanism, it can be used as a service that can be repaid with the same or a different currency (e.g., agonistic support: Seyfarth, 1977; food: de Waal, 1997). These benefits can account for the high frequency of allogrooming in certain species, which exceeds hygienic requirements. The emotional perspective on animal social behavior emphasized by the present study thus provides further support for allogrooming as a central feature of the social structure of many primate species.

\section{References}

Aureli, F. (1997). Post-conflict anxiety in nonhuman primates: The mediating role of emotion in conflict resolution. Aggressive Behavior, 23, 315-328.

Berntson, G. G., Boysen, S. T., Bauer, H. R., \& Torello, M. S. (1989). Conspecific screams and laughter: Cardiac and behavioral reactions of infant chimpanzees. Developmental Psychobiology, 22, 771-787.

Berntson, G. G., Quigley, K. S., Jang, J. F., \& Boysen, S. T. (1990). An approach to artifact identification: Application to heart period data. Psychophysiology, 27, 586-598. 
Boccia, M. L., Reite, M., \& Laudenslager, M. (1989). On the physiology of grooming in a pigtail macaque. Physiology and Behavior, 45, 667-670.

Boysen, S. T., \& Berntson, G. G. (1989). Conspecific recognition in chimpanzee (Pan troglodytes): Cardiac responses to significant others. Journal of Comparative Psychology, 103, 215-220.

Cacioppo, J. T., Klein, D. J., Berntson, G. G., \& Hatfield, E. (1993). The psychophysiology of emotion. In M. Lewis, \& J. M. Haviland (Ed.), The handbook of emotions (pp. 119-142). New York: Guilford Press.

Clarke, A. S., Mason, W. A., \& Mendoza, S. P. (1994). Heart rate patterns under stress in three species of macaques. American Journal of Primatology, 33, 133-148.

Crook, J. H. (1989). Introduction: Socioecological paradigms, evolution and history. Perspectives for the 1990s. In V. Standen \& R. Foley (Eds.), Comparative socioecology: The behavioural ecology of humans and other mammals (pp. 1-36). Oxford, England: Blackwell Scientific.

Davidson, R. J., \& Sutton, S. K. (1995). Affective neuroscience: The emergence of a discipline. Current Opinion in Neurobiology, 5, 217-224.

de Waal, F. B. M. (1992). Complementary methods and convergent evidence in the study of primate social cognition. Behaviour, $118,297-320$.

de Waal, F. B. M. (1997). The chimpanzee's service economy: Food for grooming. Evolution and Human Behavior, 18, 375386.

de Waal, F. B. M., \& Luttrell, L. M. (1985). The formal hierarchy of rhesus monkeys: An investigation of the bared-teeth display. American Journal of Primatology, 9, 73-85.

de Waal, F. B. M., \& Luttrell, L. M. (1989). Toward a comparative socioecology of the genus Macaca: Different dominance styles in rhesus and stumptail macaques. American Journal of Primatology, 19, 83-109.

Drescher, V. M., Gantt, W. H., \& Whitehead, W. E. (1980). Heart rate response to touch. Psychosomatic Medicine, 42, 559-565.

Drescher, V. M., Hayhurst, V., Whitehead, W. E., \& Joseph, J. A. (1982). The effects of tactile stimulation on pulse rate and blood pressure. Biological Psychiatry, 17, 1347-1352.

Ekman, P., Levenson, R. W., \& Friesen, W. V. (1983, September 16). Autonomic nervous system activity distinguishes among emotions. Science, 221, 1208-1210.

Feh, C., \& De Mazieres, J. (1993). Grooming at a preferred site reduces heart rate in horses. Animal Behaviour, 46, 1191-1194.

Fredrikson, M. (1989). Psychophysiological and biochemical indices in "stress" research: Applications to psychopathology and pathophysiology. In G. Turpin (Ed.), Handbook of clinical psychophysiology (pp. 241-279). New York: Wiley.

Frijda, N. H. (1994). Emotions are functional, most of the time. In P. Ekman \& R. J. Davidson (Eds.), The nature of emotionFundamental questions (pp. 112-122). New York: Oxford University Press.

Goosen, C. (1987). Social grooming in primates. In G. Mitchell, \& J. Erwin (Eds.), Comparative primate biology, Vol 2b: Behavior, cognition and motivation (pp. 107-131). New York: Alan R. Liss.

Graham, F. K. (1979). Distinguishing among orienting, defensive, and startle reflexes. In H. D. Kimmel, E. H. van Olst, \& J. F. Orlebeke (Eds.), The orienting reflex in humans (pp. 137-167). Hillsdale, NJ: Erlbaum.

Gray, J. A. (1987). The psychology of fear and stress. Cambridge, England: Cambridge University Press.

Kaplan, J. R., Manuck, S. B., \& Gatsonis, C. (1990). Heart rate and social status among male cynomolgus monkeys (Macaca fascicu- laris) housed in disrupted social groups. American Journal of Primatology, 21, 175-187.

Lazarus, R. S. (1991). Emotion and adaptation. New York: Oxford University Press.

LeDoux, J. E. (1995). In search of an emotional system in the brain: Leaping from fear to emotion and consciousness. In M. S. Gazzaniga (Ed.), The cognitive neurosciences (pp. 1049-1061). Cambridge, MA: MIT Press.

Levenson, R. W. (1992). Autonomic nervous system differences among emotions. Psychological Science, 3, 23-27.

Lott, D. F. (1991). Intraspecific variation in the social system of wild vertebrates. Cambridge, England: Cambridge University Press.

Maestripieri, D., Schino, G., Aureli, F., \& Troisi, A. (1992). A modest proposal: Displacement activities as indicators of emotions in primates. Animal Behaviour, 44, 967-979.

Manuck, S. B., Kaplan, J. R., Adams, M. R., \& Clarkson, T. B. (1989). Behaviorally elicited heart rate reactivity and atherosclerosis in female cynomolgus monkeys (Macaca fascicularis). Psychosomatic Medicine, 51, 306-318.

Manuck, S. B., Kaplan, J. R., \& Clarkson, T. B. (1986). Atherosclerosis, social dominance, and cardiovascular reactivity. In T. H. Schmidt, T. M. Dembrosky, \& G. Blumchen (Eds.), Biological and psychological factors in cardiovascular disease (pp. 461475). Berlin: Springer-Verlag.

Miller, R. E. (1967). Experimental approaches to the physiological and behavioral concomitants of affective communication in rhesus monkeys. In S. A. Altmann (Ed.), Social communication among primates (pp. 125-134). Chicago: University of Chicago Press.

Ninan, P. T., Insel, T. M., Cohen, R. M., Cook, J. M., Skolnik, P., \& Paul, S. M. (1982, December 24). Benzodiazepine receptormediated experimental "anxiety" in primates. Science, 218 , 1332-1334

Ohman, A. (1993). Fear and anxiety as emotional phenomena: Clinical phenomenology, evolutionary perspectives, and information-processing mechanisms. In M. Lewis \& J. M. Haviland (Eds.), The handbook of emotions (pp. 511-536). New York Guilford.

Panksepp, J. (1989). The psychobiology of emotions: The animal side of human feelings. In G. Gainotti \& C. Caltagirone (Eds.), Emotions and the dual brain (pp. 31-55). Berlin, Germany: Springer-Verlag.

Pavani, S., Maestripieri, D., Schino, G., Turillazzi, P. G., \& Scucchi, S. (1991). Factors influencing scratching behavior in long-tailed macaques. Folia Primatologica, 57, 34-38.

Porges, S. W. (1995). Orienting in a defensive world: Mammalian modifications of our evolutionary heritage. A polyvagal theory. Psychophysiology, 32, 301-318.

Rasmussen, K. L. R., \& Suomi, S. J. (1989). Heart rate and endocrine responses to stress in adolescent male rhesus monkeys on Cayo Santiago. Puerto Rico Health Science Journal, 8 65-71.

Rolls, E. T. (1995). A theory of emotion and consciousness, and its application to understanding the neural basis of emotion. In M. S. Gazzaniga (Ed.), The cognitive neurosciences (pp. 10911106). Cambridge, MA: MIT Press.

Schino, G., Perretta, G., Taglioni, A. M., Monaco, V., \& Troisi, A. (1996). Primate displacement activities as an ethopharmacological model of anxiety. Anxiety, 2, 186-191.

Schino, G., Scucchi, S., Maestripieri, D., \& Turillazzi, P. G. (1988). Allogrooming as a tension-reduction mechanism: A behavioral approach. American Journal of Primatology, 16, 43-50.

Seyfarth, R. M. (1977). A model of social grooming among adult female monkeys. Journal of Theoretical Biology, 65, 671-698. 
Smith, O. A., Astley, C. A., Chesney, M. A., Taylor, D. J., \& Spelman, F. A. (1986). Personality, stress and cardiovascular disease: Human and nonhuman primates. In B. Lown, A. Malliani, \& M. Prosdomici (Eds.), Neural mechanisms and cardiovascular disease: Fidia research series (Vol. 5, pp. 471-484). Padova, Italy: Liviana Press.

Smith, O. A., Astley, C. A., Spelman, F. A., Golanov, E. V., Chalyan, V. G., Bowden, D. M., \& Taylor, D. J. (1993). Integrating behavior and cardiovascular responses: Posture and locomotion. I: Static analysis. American Journal of Physiology, 265, R1458-R1468.

Stohr, W. (1988). Longterm heartrate telemetry in small mammals: A comprehensive approach as a prerequisite for valid results. Physiology and Behavior, 43, 567-576.

Suomi, S. J. (1991). Uptight and laid-back monkeys: Individual differences in the response to social challenges. In S. E. Brauth,
W. S. Hall, \& R. J. Dooling (Eds.), Plasticity of development (pp. 27-56). Cambridge, MA: MIT Press.

Terry, R. (1970). Primate grooming as a tension reduction mechanism. The Journal of Psychology, 76, 129-136.

Troisi, A., \& Schino, G. (1987). Environmental and social influences on autogrooming behaviour in a captive group of Java monkeys. Behaviour, 100, 292-302.

Waxer, P. H. (1977). Nonverbal cues for anxiety: An examination of emotional leakage. Journal of Abnormal Psychology, 86, $306-314$.

Received July 25, 1997

Revision received July 1,1998

Accepted July 7, 1998

\section{Low Publication Prices for APA Members and Affiliates}

Keeping you up-to-date. All APA Fellows, Members, Associates, and Student Affiliates receive-as part of their annual dues-subscriptions to the American Psychologist and APA Monitor. High School Teacher and International Affiliates receive subscriptions to the APA Monitor, and they may subscribe to the American Psychologist at a significantly reduced rate. In addition, all Members and Student Affiliates are eligible for savings of up to $60 \%$ (plus a journal credit) on all other APA journals, as well as significant discounts on subscriptions from cooperating societies and publishers (e.g., the American Association for Counseling and Development, Academic Press, and Human Sciences Press).

Essential resources. APA members and affiliates receive special rates for purchases of APA books, including the Publication Manual of the American Psychological Association, and on dozens of new topical books each year.

Other benefits of membership. Membership in APA also provides eligibility for competitive insurance plans, continuing education programs, reduced APA convention fees, and specialty divisions.

More information. Write to American Psychological Association, Membership Services, 750 First Street, NE, Washington, DC 20002-4242. 